\title{
Factors Affecting the Capacity of Accounting Software in Controlling Frauds and Errors in Small and Medium Enterprises (Smes): A Case Study of SMEs in Hanoi, Vietnam
}

\section{Ngo Thi Thu Hang ${ }^{1}$, Vu Thi Hai ${ }^{1}$, Tran Quang Trung ${ }^{1}$, Vu Manh Chien $^{2}$, Nguyen Thi Hong Nga ${ }^{3}$}

${ }^{1}$ Faculty of Accounting and Business Management, Vietnam National University of Agriculture, Hanoi 131000, Vietnam

${ }^{2}$ Faculty of Accounting \& Auditing - Vietnam University of Commerce, Hanoi 122868, Vietnam

${ }^{3}$ Faculty of Accounting and Auditing - Hanoi University of Industry, Hanoi 129000, Vietnam

\begin{abstract}
Financial accounting information has impacted the operation of enterprises, especially SMEs. With the development of technology, digital accounting applications are playing an increasingly important role in minimizing mistakes, and ensuring the accuracy and timeliness of accounting information. Using multiple discriminant analyses, this study confirmed the significance of accounting software in reducing frauds and errors in SMEs' businesses despite some drawbacks. It showed that the managers' ability to access the software and the decentralization of power in accessing the accounting software were the two key factors deciding the success/failure of applying accounting software to control frauds and errors. In addition, smart applications of the accounting software positively contributed to the elimination of frauds in enterprises. Based on these results, recommendations are drawn for SMEs, such as investing more in smart applications of accounting software, as well as updating knowledge about accounting for management, in order to get more advantages from accounting software applications for their business in the long term.
\end{abstract}

\section{Keywords}

Accounting software, frauds and errors, SME

\section{Introduction}

In the modern world, technology has taken a dominant role.

Received: June 13, 2020 Accepted: March 2, 2021

Correspondence to ngothuhang@vnua.edu.vn
Information technology has significantly changed the accounting profession in recent decades through the advent of countless accounting software, and the development of the internet and cloud computing. These technologies have transformed the profession in 
many aspects, from the nature of accounting to the products of accounting works, and even in the structure of accounting systems in a business (Amidu et al., 2011). According to Deshmukh (2006), there has not been a standard definition but the term "digital accounting" refers to the representation of accounting information in a digital format, as well as the changes in accounting due to computing and networking technologies. In a word, digital technology has broken the boundaries of traditional accounting systems, both literally and figuratively.

Precise and timely economic information given by the accounting department will actively assist managers both in making decisions and managing their business. However, an incorrect accounting system could result in many serious problems for a company, especially in small and medium enterprises (SMEs) (Chakraborty, 2015). Although errors are inherent to accounting and materially impact the quality of a financial report, this issue is often neglected when the design of accounting systems is evaluated (Christensen, 2010). The evolution of information technology in accounting has been expected to solve the above problems. Previous inefficient traditional paper-based manual accounting methods have been gradually improved through the implementation of computerized accounting information systems (Zakaria et al., 2011). Saving the amount of labour and time for accounting work, providing more precise and timely information, and increasing the convenience for the related parties in economic transactions are inherently beneficial not only for the enterprises but also for all the users of the enterprises' financial information as well as the whole community. As one of the important elements of the internal control system, the accounting system is expected to powerfully control frauds and errors, especially with the support of advanced technology and the concept of business intelligence (BI) (Graham, 2015). A survey conducted in 2019 by The Association of Chartered Certified Accountants (UK) found that out of 4,264 accountancy and finance professionals globally, including members, affiliates, and students, $89 \%$ considered digital skills necessary or very necessary in their industry and $63 \%$ believed that they had the right level of digital skills for their roles (ACCA, 2020).

For all kinds of businesses, frauds and errors during the running process have frequently caused serious problems. According to the International Standard on Auditing 240, fraud refers to "an intentional act by one or more individuals among management, those charged with governance, employees, or third parties, involving the use of deception to obtain an unjust or illegal advantage", while error refers to "an unintentional misstatement in the financial statements, including the omission of an amount or disclosure". By intentionally or unintentionally affecting the assets or the decision-making system, errors and fraud can lead to financial losses and, in some cases, even force companies to lay off staff or collapse (Gee et al., 2011). According to the Association of Certified Fraud Examiners (ACFE), the estimated fraud losses for all businesses in the world totalled nearly 2.9 trillion USD in 2009 , more than 30 percent of which occurred in small and medium-sized companies (Morey, 2010). Notably, the Centre for Economics Business and Research (CEBR) in 2016 evaluated that the increasing incidences of fraud and errors, and the increasing magnitude and impacts of fraud and online crime were the unfortunate outcomes which coincided with the fast growth and innovations of enterprises in the Asia Pacific region. Fifty-nine percent of the firms involved in this research forecasted that frauds would increase in the next five years, with over half of the surveyed firms $(51 \%)$ indicating that they are spending more time and investment on fraud prevention.

Despite the significant role of digital accounting in business management and its widespread use, research on this topic has been limited in scope. Existing research has focused on analyzing the performances of e-accounting of other countries such as in Malaysia (Zakaria et al. , 2011), Ghana (Amidu et al. , 2011), or in in the UK, mainland China, India, Singapore, Russia, and Brazil but not including Vietnam (ACCA, 2020). Besides, there is little research 
about the negative impacts of digital accounting on business management, except for some predictions about the issue of cybercriminal activities which have become a challenge for the accounting profession (Brozovsky \& Luo, 2013). These issues raise the question of why do businesses follow the trend of investing more in digital accounting as well as in advanced technology when there are more potential risks that the entrepreneurs must cope with? Focusing on SMEs as the research subjects, this research aimed to explore the hidden reasons why some companies benefit from accounting software while others do not. Furthermore, despite many policies to support the development of SMEs in Vietnam, such as supplying formal credit capital, and enhancing human capacity, land, and market connections (Phung The Dong, 2019), so far there has been limited research about digital accounting applications in SMEs, which could lead to better policies/intervention to support SMEs in this regard. Therefore, this research sought to examine the role of accounting software in controlling frauds and errors in SMEs in Hanoi, Vietnam, as well as to discover the factors that support and impede SMEs from utilizing accounting software in the elimination of frauds and errors. The research results could be of help to managers in improving accounting systems and gaining the maximum benefits from digital accounting software in their enterprises as well as policy-makers wishing to design effective interventions to support SMEs.

\section{Methodology}

\section{Research site and sample selection}

Hanoi is the capital of Vietnam and has the second-largest economic scale of the country. After expanding administrative boundaries in 2008 , Hanoi now covers an area of $334,470.02$ hectares and had a population of over 8 million people in 2019. Its GRDP per capita in 2019 reached VND 127.6 million. Hanoi contributes about $2.1 \%$ of the national GDP growth, $19 \%$ of the total budget revenue, and $6 \%$ of the country's export turnover (Hanoi Statistics Office, 2020). According to the White Book on Vietnamese
Businesses 2020 released by the Ministry of Planning \& Investment on 28 April 2020, the total number of enterprises in Hanoi in 2018 increased to 129,556 ; and $97.5 \%$ of those were small and medium enterprises, which created jobs for 1.2 million workers in this area.

The sampling group consisted of 150 randomly chosen SMEs in Hanoi that had been operating for more than five years. Five years was considered the appropriate length of time for both the directors and the accountants to assess the changes of the accounting profession as well as their impacts on the enterprise and the accountants. Also, after five years in operation, each of the SMEs should have undergone at least one external check by taxation authorities. After invalid responses were removed, only 131 responses were used for this research. Fifty-eight enterprises $(44.3 \%)$ were in commercial sectors. The majority of the enterprises (108) had fully functioning accounting departments that performed duties ranging from collecting receipts to book recording and reporting. However, half of them had never been checked by the parent company or external auditors (Figures 1, 2, and 3).

\section{Data collection}

Primary data in this research were collected using a semi-structured questionnaire for interviewees (accountants or managers). The questions focused on basic information about their accounting systems, the involvement of accountants and managers in the accounting system, the application status of the accounting software in their companies; the frequency and scale of frauds and errors occurring after using digital accounting; their opinions on the impact of digital accounting on frauds and errors, and their perceived benefits and problems of applying digital accounting.

\section{Data analysis}

Descriptive statistics were used to examine the interviewees' evaluations of the impacts of accounting software on the controlling of errors and frauds in their enterprise (in terms of the frequency and scale of the errors and frauds), 


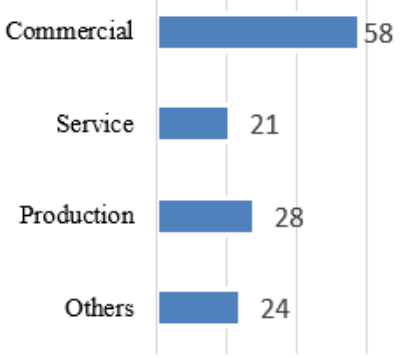

Figure 1. Number of enterprises categorised based on type of business

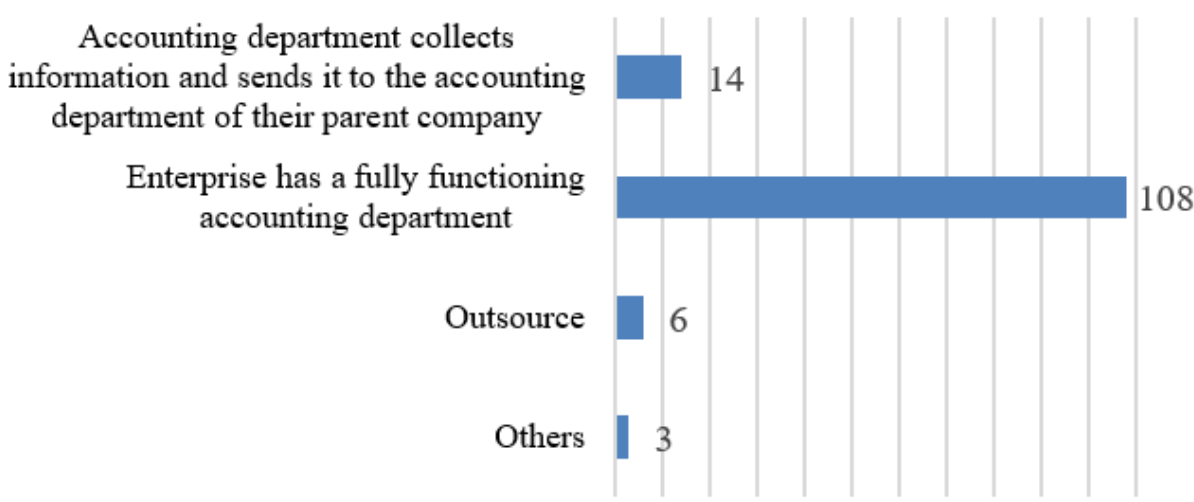

Figure 2. Number of enterprises categorised based on type of accounting models

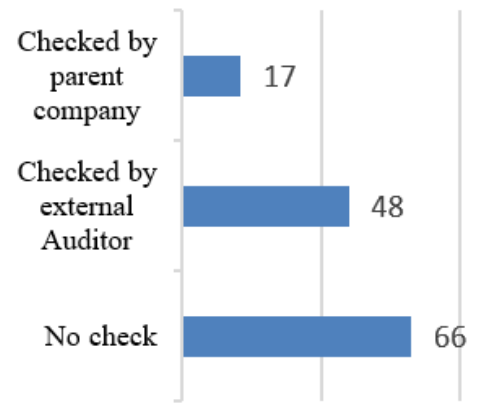

Figure 3. Number of enterprises categorised based on the type of external checks for the financial informations

using a Likert scale with five levels as follows: 1 $=$ Increase, 2 = Slightly increase, 3 = No changes, 4 = Slightly decrease, and $5=$ Decrease.

Multiple discriminant analysis was also used to measure the impacts (Brown, 1998; Hoang Trong \& Chu Nguyen Mong Ngoc, 2008) of factors on the application of accounting software in controlling business risks. Based on the research of Güney (2014), Ghasemi et al. (2011), and Jordan (1999), the independent variables used in the study were: (1) Experience of the chief accountant; (2) Experience of the accountants who manage the software; (3) The frequency of maintenance of the software; (4) Smart applications in the accounting software;
(5) The access of managers to the accounting software, and (6) The decentralization of power in accessing the accounting software. This was performed by examining the differences among three groups, categorized by the success/failure of the applications of accounting software in controlling errors and frauds in their business: Group 1 consisted of companies in which accounting software has had positive impacts in controlling frauds and errors; Group 2 consisted of companies in which accounting software has had no impact in controlling frauds and errors; and Group 3 consisted of companies in which accounting software has had negative impacts in controlling frauds and errors. This analysis was 
used to define which factor among the six factors above influenced the success/failure of the application of accounting software in controlling errors and frauds in those companies.

\section{Results and Discussion}

The role of accounting software in controlling the frauds and errors in SMEs of Hanoi, Vietnam

A majority of the interviewed managers and accountants, who had from 1 year to more than 10 years' experience in using accounting software for their daily work, positively evaluated the role of accounting software in controlling frauds and errors in their business. They even evaluated accounting software as the most useful tool in reducing the frequency as well as the scale of frauds and errors, compared with other digital applications in their accounting work such as digital signatures, online sales, or internet banking (Table 1).

The application of information technology in accounting systems has great significance in preventing and detecting frauds and errors quickly. This finding is consistent with the research of Ngo et al. (2013) which indicated a negative correlation between the application of information technology to business accounting and the existence of fraud and error in that business. The reasons given were that applying information technology to management in general and accounting work in particular will create favorable conditions for managers in corporate governance and allow check comparisons to detect frauds as well as financial errors. With the support of accounting software, especially E-accounting software, the task of controlling has been improved based on the upto-date and online data, which help to eliminate data duplication and improve the centralized control of data systems (Zakaria et al. , 2011; Güney, 2014). Important features such as standard defaults and mathematical verification processes could help to ensure that the company's accounting ledgers are always in balance and do not contain any unbalance errors. Moreover, electronically transferring information is always more accurate and timely than handing based on the manual accounting system (Ghasemi et al., 2011). In addition, the application of accounting software also enables easier and more effective supervision of finances and other judicial issues, which certainly supports fraud reduction (Güney, 2014). While the conventional manual approach is more suitable for discovering anomalies due to unintentional errors found regularly in data based on the "double-entry" principle, computer-based approaches could detect even intentional frauds by an employee in selected financial transactions, or frequently controlling full populations of data (Wong \& Venkatraman, 2015).

However, the results from the survey

Table 1. Evaluation of managers and accountants about the impact of technology applications

\begin{tabular}{ccccc}
\hline & \multicolumn{2}{c}{ Impact in controlling frauds } & \multicolumn{2}{c}{ Impact in controlling frauds } \\
\cline { 2 - 5 } & $\begin{array}{c}\text { Reduce the frequency } \\
\text { of frauds }\end{array}$ & $\begin{array}{c}\text { Reduce the scale of } \\
\text { frauds }\end{array}$ & $\begin{array}{c}\text { Reduce the frequency } \\
\text { of frauds }\end{array}$ & $\begin{array}{c}\text { Reduce the scale of } \\
\text { frauds }\end{array}$ \\
\hline Accounting Software & 4.49 & 4.39 & Accounting Software & 4.49 \\
Digital Signatures & 4.15 & 4.12 & Digital Signatures & 4.15 \\
Online Taxes & 4.23 & 4.26 & Online Taxes & 4.23 \\
Online Sales & 3.58 & 3.79 & Online Sales & 3.58 \\
Internet Banking & 4.03 & 4.10 & Internet Banking & 4.03 \\
Antivirus Software & 3.94 & 4.03 & Antivirus Software & 3.94 \\
Intranet Applications & 4.25 & 3.89 & Intranet Applications & 4.25 \\
Online Backups & 3.95 & 4.04 & Online Backups & 3.95 \\
\hline
\end{tabular}

Note : 1: Increase; 2: Slightly increase; 3: No changes; 4: Slightly decrease; 5: Decrease 
showed that besides the majority of the managers and accountants who had positive views about the effectiveness of accounting software in controlling errors and frauds, $9 \%$ of the interviewed SMEs said that the software had no impact in controlling errors and frauds. Moreover, $10 \%$ of the interviewed SMEs indicated that it had negative impacts in controlling errors (Figure 4). Many reasons for these results have been reported based on several case studies. The first reason is the limitation in the capacity of accountants in managing accounting software in the context of continuous development of information technology. The use of information technology systems in the organization may also present some challenges for the accountants. As the technology offers accountants various methods for extracting detailed and precise financial information, the risk of poor accountability and loss of confidentiality, therefore, increases ((Jordan, 1999) cited in (Zakaria et al. , 2011)). Similarly, the risk of cybercriminals tampering with a firm's data and stealing valuable informationwithout ever seeing or coming into contact with the victim - can be seen as an unfortunate consequence of these advances (Brozovsky \& Luo, 2013). Second, the application of accounting software in the financial system also increases a businesses' dependence on equipment platforms as well as other external conditions such as electric power and internet access. Most surveyed SMEs in this study had experienced the problems of a power cut and sudden interruption of their internet connection, like many Ghanaian SMEs (Amidu et al. , 2011). Therefore, most of the SMEs contacted considered frequent breakdowns of their accounting system a serious problem which then led to inaccurate reports generated by the accounting systems, an inability to import/export financial data, and an inability to fully comprehend and interpret the results from the system. Countless errors have been found as the results of these situations, which take a lot of time for the accountants to rework or fix. The last reason is more related to the causes of the frauds. Along with the advantages of a paperless accounting system, the application of hi-tech in the accounting work also increases the chance of the intentional modifications of financial data by unethical accountants. This can allow accountants to easily make fraudulent changes if the managers do not really understand the meaning of financial figures or the actual financial status of the business. The limited accounting knowledge of many managers also causes difficulties in controlling their accountants. This opportunity has made accounting manipulation of financial figures to be more easily overlooked by managers.

\section{Factors affecting the success of accounting software application in controlling the business frauds and errors}

Given the fact that $81 \%$ of the surveyed SMEs had succeeded in using accounting software to control business frauds and errors, $9 \%$ found there was no impact, and $10 \%$ found that it had negative impacts in these controlling tasks, the SMEs were divided into three groups for the multiple discriminant analysis tests, which aimed to find out the key factors affecting successes/failures. The results, shown in Table 2 and Table 3, indicated that the role of the managers' access to the accounting software and the decentralization power in accessing the accounting software were the important factors to the success or failure of the SME in using accounting software to control frauds and errors.

Controls by the managers, namely the board of directors and the chief of the financial department, on financial accounting matters were vital in controlling and preventing mistakes. Luckily, accounting software packages designed for SMEs are usually basic programs created with non-accountant thinking in mind, which allows business owners and managers to perform traditional accounting functions without much formal training or technical accounting knowledge. Even more, small business owners or managers may also be able to transfer this information electronically to their public accountant for tax purposes by themselves (Ghasemi et al. , 2011). A similar idea was found in the research of Zhou 


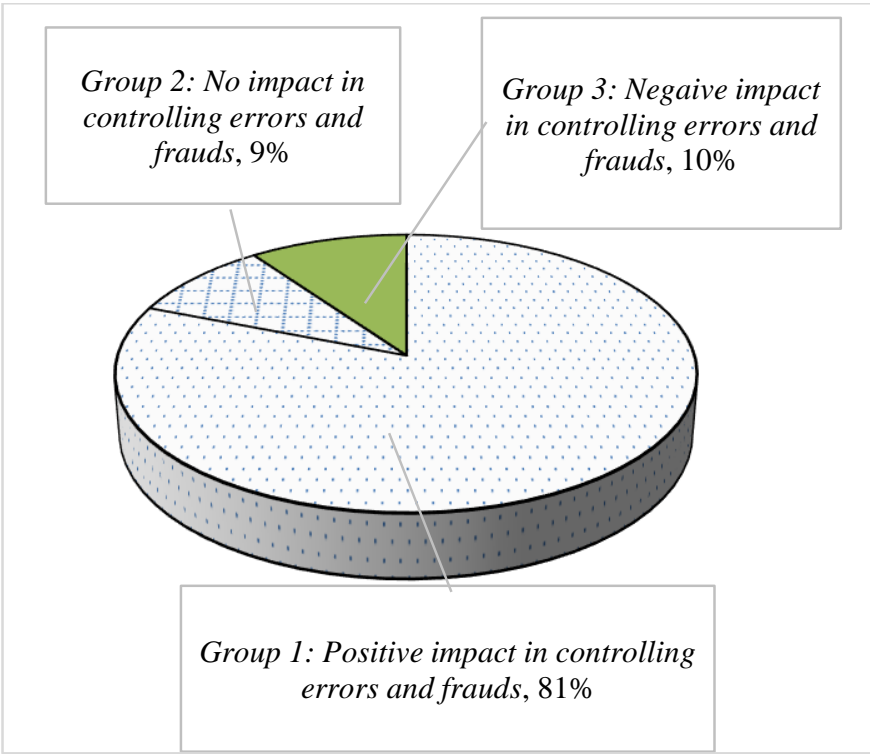

Figure 4. Proportions of SMEs categorized by impacts of accounting software in controlling errors and frauds

Table 2. Multiple discriminant analysis tests on the factors affecting the success of accounting software application in controlling errors

\begin{tabular}{cccccc}
\hline Factors & Wilks' Lambda & $\mathrm{F}$ & $\mathrm{df1}$ & $\mathrm{df2}$ & Sig. \\
\hline Experience of the chief accountant & 0.988 & 0.771 & 2 & 128 & 0.465 \\
\hline Experience of the accountants who manage the software & 0.991 & 0.565 & 2 & 128 & 0.570 \\
\hline The frequency of maintenance of the software & 0.985 & 0.955 & 2 & 128 & 0.387 \\
\hline Smart applications in the accounting software & 0.973 & 1.751 & 2 & 128 & 0.178 \\
\hline The access of managers to the accounting software & 0.919 & 5.659 & 2 & 128 & 0.004 \\
\hline The decentralization of power in accessing the accounting software & 0.763 & 19.917 & 2 & 128 & 0.000 \\
\hline
\end{tabular}

Note:

Experiences of the chief accountant $=$ number of experience years of the chief accountant

Experience of accountants who manage the software = number of experience years of the accountant who manages the accounting software

The frequency of maintenance of the software = Periodical (every year) / Sometimes (once every 2-3 years) / Never

Smart applications in accounting software = High level / Average level/ Low level / No applications

The access of managers to the accounting software = Managers have access to the accounting software: Yes/No

The decentralization power in access accounting software = High level / Average level/ Low level / Free for everyone to access.

(2010) (cited in (Maseko \& Manyani, 2011) which proposes the use of accounting software by the business owner or the managers in SMEs to improve accounting practices. Moreover, the involvement of managers in the financial system can help them to recognize the potential risks in the financial accounting of their business, as well as find and recruit experienced and qualified staff adequately. This, directly or indirectly, could help to reduce the inherent risks and control risks in their business (Ngo Thi Thu Hang et al., 2013). Therefore, governance was seen as one of the mechanisms that could effectively safeguard the interests of the business owner, as well as ensure effective monitoring. In other words, the important part of the management's duty is to promote an effective internal control structure to protect the entity's assets and to maintain the credibility of financial reporting (Hussain et al., 2016).

The second factor in the success of the accounting software in controlling errors and frauds was the decentralization of power in accessing the accounting software, which means 
Table 3. Multiple discriminant analysis tests on the factors affecting the success of accounting software application in controlling fraud

\begin{tabular}{cccccc}
\hline Factors & Wilks' Lambda & $\mathrm{F}$ & $\mathrm{df1}$ & $\mathrm{df2}$ & Sig. \\
\hline Experience of the chief accountant & 0.973 & 1.754 & 2 & 128 & 0.177 \\
Experience of the accountants who manage the software & 0.966 & 2.221 & 2 & 128 & 0.113 \\
The frequency of maintenance of the software & 0.991 & 0.579 & 2 & 128 & 0.562 \\
Smart applications in the accounting software & 0.906 & 6.642 & 2 & 128 & 0.002 \\
The access of managers to the accounting software & 0.886 & 8.237 & 2 & 128 & 0.000 \\
The decentralization of power in accessing the accounting software & 0.840 & 12.230 & 2 & 128 & 0.000 \\
\hline
\end{tabular}

Note:

Experience of the chief accountant: number of experience years of the chief accountant

Experience of accountants who manage the software: number of experience years of the accountant who manages the accounting software

The frequency of maintenance of the software: Periodical (every year) / Sometimes (once every 2-3 years) / Never

Smart applications in the accounting software: High level / Average level/ Low level / No application

Managers have access to the accounting software: Yes/No

The decentralization of power in accessing the accounting software: High level / Average level/ Low level / Free for everyone to access

that each accountant can access only the procedure or part of the accounting software related to his/her work. The more this mechanism was developed in the accounting software, the fewer frauds and errors occurred in the business. Consistent with this finding, the research of Ghasemi et al. (2011) about the impact of Information Technology (IT) on modern accounting systems also indicated that the accuracy of financial information was improved by limiting the number of accountants who have access to the full procedure of the accounting cycle. As for the reason, less access by accountants ensures that financial information was adjusted only by qualified supervisors.

Furthermore, the smart applications in the accounting software have also been considered as one of the important factors in controlling frauds, but not a significant factor in controlling errors (Tables 2 and 3). The smart applications here refer to online access that allow data to be updated via many methods such as smartphones, tablets, laptops, and integrated with electronic invoices, online tax returns, and internet banking services, which support early detection of frauds by instantly checking and informing the whole system. While business errors can be controlled by the basic functions of accounting software (for example, computerized systems will not allow journal entries to be out of balance when posting, ensuring that individual transactions are properly recorded), these smart applications are expected to play a remarkable role to eliminate frauds, which are dissimulated and therefore more difficult to detect than business errors.

\section{Conclusions and Implications}

\section{Conclusions}

Generally, accounting software is becoming an important part of the accounting system in all businesses because it does not only support recording data and making financial reports timely and accurately, but also plays an important role in controlling frauds and errors in businesses. The results of this study confirmed the effectiveness of accounting software with these controlling tasks, with evidence from $81 \%$ of the surveyed SMEs who succeeded in applying it to reduce the frequency and scale of frauds and errors in their firms. However, some SMEs reported no impacts (9\%), or even negative impacts $(10 \%)$ of accounting software on controlling frauds and errors. The results of the tests showed that the access of managers to the accounting software and the decentralization of power in accessing the accounting software were the two major factors in the success/failure of using software to control frauds and errors. In addition, smart applications in the accounting 
software were found to impact the effectiveness of this practice.

\section{Implications}

Given the above results, this research suggests that SMEs should be aware of the longterm benefits of appropriate investments in accounting software because failure to apply this measure may lead to significant losses of resources in their business. More expensive investments in accounting software for additional smart applications could be worthy of positive contributions to controlling and reducing frauds.

Secondly, a managers' fundamental knowledge of the accounting profession is essential, which not only helps them understand accounting information but also gives them strict control over their accountants. Therefore, they should consider taking a training course on elementary principles of accounting. With some basic understanding of accounting in general and accounting software in particular, the involvement of the directors/managers in the financing system certainly would be more effective and efficient, especially in the era of the recent Industry 4.0 revolution.

\section{References}

ACCA (2020).The digital accountant: Digital skills in a transformed world. Retrieved from https://www.accaglobal.com/content/dam/ACCA_Glo bal/professional-insights/digital_accountant/pidigital-accountant.pdf on December 20th 2020.

Amidu M., Effah J. \& Abor J. (2011). E-accounting practices among small and medium enterprises in Ghana. Journal of Management Policy and Practice. 12(4): 146-155.

Brown C. E. (1998). Applied Multivariate Statistics in Geohydrology and Related Sciences. Springer. 272 pages

Brozovsky J. \& Luo J. (2013). Digital forensics: a new challenge for accounting professionals. Strategic Finance. 94(11): 37-42.

CEBR (2016). The economic of fraud: Mitigating risk amidst fast growth and innovation. Experian Public. 78 pages

Chakraborty A. (2015). Impact of Poor Accounting Practices on the Growth and Sustainability of SMEs.
The International Journal of Business \& Management. 3(5): 227-231.

Christensen J. (2010). Accounting errors and errors of accounting. The Accounting Review. 85(6): 18271838.

Deshmukh A. (2006). Digital accounting: The effects of the internet and ERP on accounting. IGI Global. 385 pages

Gee J., Button M. \& Brooks G. (2011). The financial cost of fraud. MacIntyre Hudson/CCFS. London: PKF/CCFS. 78 pages

Ghasemi M., Shafeiepour V., Aslani M. \& Barvayeh E. (2011). The impact of Information Technology (IT) on modern accounting systems. Procedia-Social and Behavioral Sciences. 28: 112-116.

Graham L. (2015). Internal control audit and compliance. John Wiley \& Sons. 377 pages

Güney A. (2014). Role of technology in accounting and eaccounting. Procedia-Social and Behavioral Sciences. 152: 852-855.

Hanoi Statistics Office (2020). Hanoi 2019 Annual Statistic Statistic Publishing House. 670 pages

Hoang Trong \& Chu Nguyen Mong Ngoc (2008). Analysis Data for Research with SPSS. (2). Hong Ngoc Publisher. University of Economic Hochiminh City. 177 pages

Hussain A. R., Hasnan S., Sanusi Z. \& Mahenthiran S. (2016). Accounting misstatements and monitoring mechanisms: A literature review. Asia Pacific Journal of Accounting and Finance. 3(1): 32-44.

Jordan A. S. (1999). The impact technology is having on the accounting profession. Journal of Accounting Education. 2(17): 341-348.

Maseko N. \& Manyani O. (2011). Accounting practices of SMEs in Zimbabwe: An investigative study of record keeping for performance measurement (A case study of Bindura). Journal of accounting and taxation. 3(8): 158-161.

Ministry of Planning \& Investment (2020). White Book on Vietnamese Businesses 2020. Statistical Publisher. 578 pages

Morey C. P. (2010).Accounting errors, fraud are common problems for small businesses. Accoungting Web. Retrieved

from https://www.accountingweb.com/aa/law-andenforcement/accounting-errors-fraud-are-commonproblems-for-small-businesses on October 15th 2018.

Ngo Thi Thu Hang, Le Thi Kim Son \& Nguyen Thi Thuy Dung (2013). Impact of Accounting Information System on the Existence of Fraud and Errors in Small and Medium-sized Enterprises. Jounal of Science and Development. 11(4): 565-573.

Phung The Dong (2019). Supporting to the development of Vietnam's small and medium-sized enterprises. Financial Journal . 10/2019. 
Symmetry 50 (2014). The top 20 accounting software products [Online]. Retrieved from http://www.symmetry50.com/blog/2014/11/8/the-top20 -accounting-software-products on on October 15 th 2018.Tipgos M. A. (2002). Why management fraud is unstoppable. The CPA Journal. 72(12): 34.

Wong S. \& Venkatraman S. (2015). Financial accounting fraud detection using business intelligence. Asian
Economic and Financial Review. 5(11): 1187-1207.

Zakaria W. Z. W., Rahman S. F. \& Elsayed M. (2011). An analysis of task performance outcomes through eaccounting in Malaysia. Journal of Public Administration and Governance. 1(2): 124-139.

Zhou L. (2010). The research on issue and countermeasures of accounting information of SMES. International Journal of Business and Management. 5(3): 223-225. 